Arch. Dis. Childh., 1966, 41, 597.

\title{
The Ductus Venosus and the Mechanism of Its Closure*
}

\author{
W. W. MEYER and J. LIND \\ From the Paediatric Clinic, Karolinska Sjukhuset, Stockholm, Sweden, and the Institute of Pathology, Mainz, Germany
}

Although recognized since Vesalius as one of the distinguishing features of the foetal circulation, the precise function of the ductus venosus is uncertain. Anatomically, it provides a direct connexion between the umbilical vein and the inferior vena cava. Functionally, it represents a bypass through which part of the oxygenated umbilical blood flows directly into the inferior vena cava. However, what portion of the umbilical venous blood flow passes through the ductus venosus in the human foetus is not yet known and has so far only been estimated approximately.

Not all species of mammals possess a ductus venosus at maturity; it disappears at an early stage of gestation in the horse and the pig. Experiments have shown that occlusion of the ductus venosus in mature foetal lambs causes no significant change in blood pressure, heart rate, or carotid oxygen saturation (Amoroso, Dawes, Mott, and Rennick, 1955). Its continued patency seems to be unnecessary for survival (Blanc, 1960). On the other hand, its absence is occasionally associated with some other malformations, and can cause portal hypertension in the neonatal period (MacMahon, 1960).

The findings concerning the structure of the ductus venosus are contradictory and the mechanism of its postnatal functional closure is not yet satisfactorily explained; nor is there any agreement concerning the time of closure after birth and the significance of its patency in the neonatal period of life.

We have therefore reviewed the published papers in the light of our own studies.

\section{Angiographic Studies of the Function and Closure of the Ductus Venosus}

In the living human foetus the function of the ductus venosus has been demonstrated by angiocardiography carried out in connexion with therapeutic abortions (Lind and Wegelius, 1949, 1954; Lind,

\footnotetext{
Received May 2, 1966.

* Supported in part by the Association for the Aid of Crippled Children, New York, N.Y., U.S.A., and the Swedish Medical Research Council to its Teratology Research Unit, Stockholm, Sweden.
}

Stern, and Wegelius, 1964; Lind, 1959, 1963). From the angiograms it can be seen that the big umbilical vein upon entering the liver gives off branches to the left and quadrate lobes of the liver, which are relatively large in foetuses and newborn infants (Fig. 1). Most of the umbilical flow is, however, divided higher up between the ductus venosus, which originates from the convex portion of the umbilical recess, and the portal sinus. The ductus venosus has a straight course and runs in the same direction as the intrahepatic part of the umbilical vein. It does not give off any branches. The inlet of the ductus venosus is opposite the outlet of the umbilical vein in the umbilical recess, which probably results in a preferential flow of the placental blood into the ductus. At midterm its diameter measured from the angiograms is about one-quarter to one-third of that of the portal sinus and slightly less than that of the stem of the portal vein. The portal sinus appears on the angiograms as a wide straight vessel from which numerous branches originate (Fig. 1). The trunk of the portal vein opens in the portal sinus and divides it into right and left parts, which after birth become right and left branches of the portal vein.

It can further be observed that the ductus venosus is visualized simultaneously with the portal sinus, while the hepatic veins, which drain the liver sinusoids, appear $\frac{1}{2}-1$ second later. The degree of opacification is less dense, probably due to the slight dilution of the contrast material. The main hepatic veins return not only umbilical vein blood but also some blood that reaches the liver by the hepatic artery. The venous return to the heart through the inferior vena cava and its afferent venous channels is pulsatile. The contrast-loaded blood is stopped during atrial systole-occasionally a reflux occursbut during the following ventricular systole the blood rushes into the dilating atria.

The proportion of umbilical blood that passes through the ductus venosus into the inferior vena cava during foetal development is not precisely known. In the lamb, flow through the ductus venosus appears to be governed, according to 


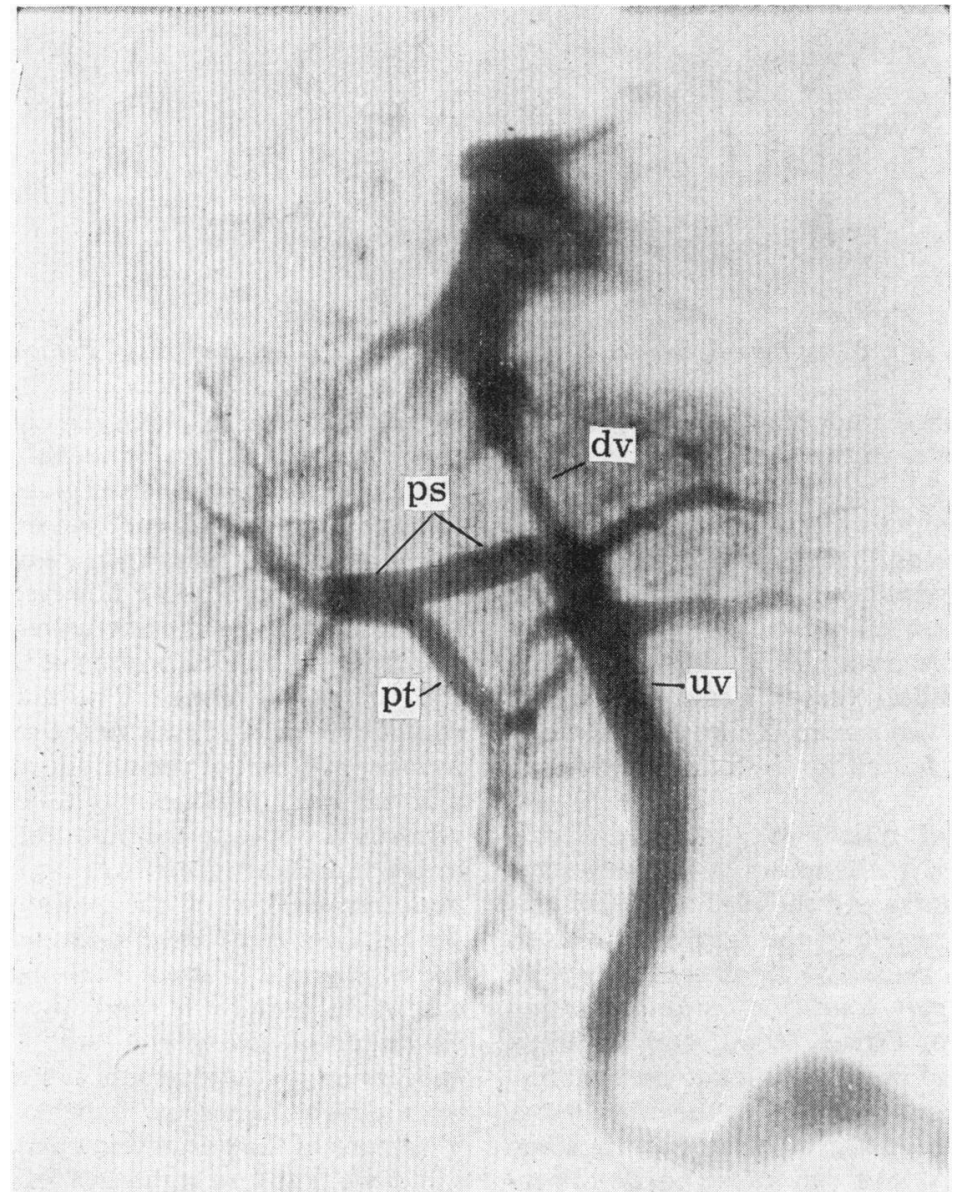

Fig. 1.-Angiogram from a living human foetus of 19 weeks. Right anterior oblique projection. Contrast injection into the umbilical vein (uv) which is well opacified as are its liver branches. Portal sinus (ps) is clearly seen and there is retrograde filling of the portal vein. The portal trunk $(p t)$ is seen to be narrower than the right and central part of the portal sinus. Much contrast medium is shunted through the ductus venosus (dv) directly into the inferior vena cava.

Barron (1942), by the shape of the umbilical recess, its walls containing smooth muscle fibres so arranged that when they contract the cavity of the recess is reduced and flow into the ductus diminished. In addition, he observed a special band of smooth muscle fibres arranged in horse-shoe fashion at the junction of the recess with the ductus. This band he thought could contribute to functional closure of the duct. Barron (1944) states, on the basis of angiograms of Franklin, Barclay, and Prichard (1940), that in the foetal lamb only a small amount of blood passes via the ductus venosus directly into the inferior vena cava, whereas most of the umbilical venous blood supplies the capillaries of the liver; this is in agreement with the anatomical conditions, since the diameter of the ductus venosus is only about one-seventh of the diameter of the umbilical vein. However, the relation of the two diameters is not decisive as to volume flow through the ductus venosus, since this is also much influenced by the peripheral vascular resistance of the liver.

The magnitude of the shunt through the ductus can be roughly estimated from our angiograms. In the great majority of cases studied, much opaque material is visualized in the heart before there is appreciable opacification of the hepatic veins (Fig. 2). The impression from human foetal angiograms at mid-term is thus that the ductus venosus functions as a low resistance bypass for the placental blood, and that a significant part of the placental venous return 
(one-third to two-thirds) reaches the heart through this channel.

Injection of contrast medium into the umbilical vein in one newborn full-term infant before and after the first breath demonstrated that the ductus venosus was widely open and permitted the passage of enough contrast medium to give visualization of the left and right heart chambers and their efferent vessels, i.e. the results correspond to those obtained by angiography at midterm.

In order to estimate the approximate distribution of the umbilical venous blood flow we have also undertaken some perfusion experiments in stillborn infants. The alterations which take place after death make such experiments hard to evaluate. Post mortem, the blood coagulation in the liver vessels and especially in the liver sinusoids increases the peripheral vascular resistance of the liver. Likewise, the insertion of a cannula in the proximal end of the ductus venosus narrows its lumen and increases its resistance also. However, the disturbing effect of post-mortem blood coagulation can be diminished by deep freezing and thawing of the

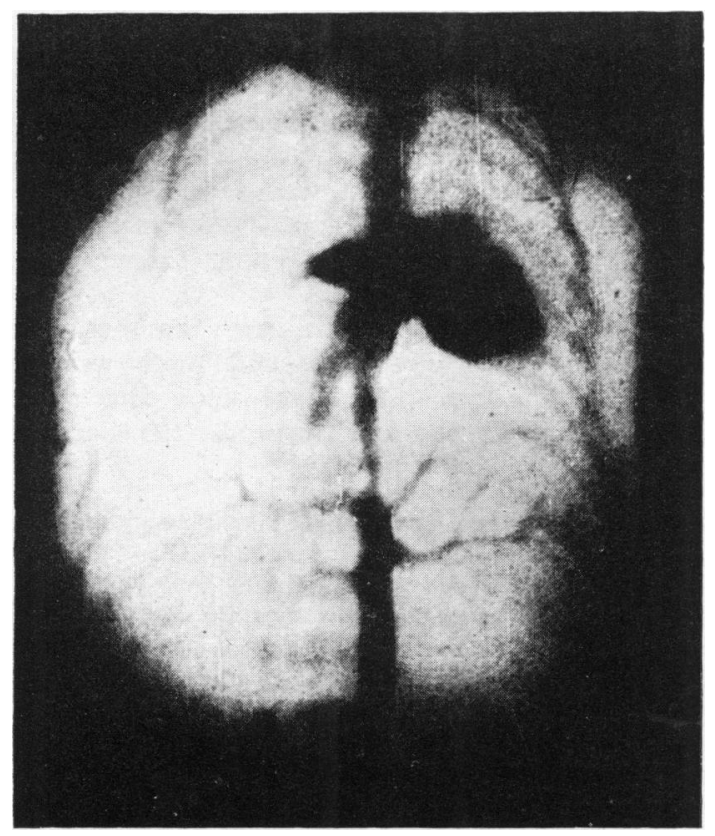

Fig. 2.-Angiogram of a living human foetus 18 weeks old. Injection of contrast medium into the umbilical vein demonstrates that the ductus venosus is widely open and permits the passage of enough contrast medium to opacify the heart chambers and their efferent vessels. Note the 3в liver. This causes haemolysis and dissolves the post-mortem blood clots. Soon after perfusion begins, the blood remnants are rinsed out of the liver, and it assumes a uniform pale yellowish colour. Immersion of the liver in saline helps to avoid an additional increase of peripheral resistance due to distortion, which can occur when the liver is placed on a hard surface during the perfusion.

The livers were perfused at room temperature with saline via the umbilical vein at a pressure of $20-30 \mathrm{~cm}$. of saline $(15-20 \mathrm{~mm} . \mathrm{Hg})$ after ligation of the trunk of the portal vein. The fluid discharged via the ductus venosus was collected, measured, and compared with the total amount of saline that was injected into the umbilical vein. More than 50 perfusions showed that $40-50 \%$ of the fluid injected into the umbilical vein passed through the ductus venosus, whereas the other half reached the inferior vena cava via the sinusoids of the liver. To what extent these results can be applied to in vivo conditions cannot yet be defined. Probably, the transport capacity of the ductus venosus in vivo varies with the volume flow through the umbilical vein and the pressure gradient across the ductus venosus. Furthermore, the antenatal intermittent contractions, i.e. temporary functional closures of the ductus venosus, which have been observed angiocardiographically in the foetal lamb (Franklin et al., 1940; Barron, 1942; Barclay, Franklin, and Prichard, 1942; Barcroft, 1946) and in the human foetus (Lind and Wegelius, 1954), could probably also influence the blood flow through this bypass.

Many studies have been carried out to observe the behaviour of the ductus venosus following birth. In the newborn baby, the ductus venosus is about $12-20 \mathrm{~mm}$. long, and through the experience of exchange transfusions we know that it allows of the passage of a No. 5-6 catheter. Angiographic studies in newborn infants have demonstrated that soon after birth the passage through the distal end of the ductus venosus is very narrow (Fig. 3 ).

Data obtained from dye-dilution curves recorded from right atrial and portal vein injections suggest that relatively small amounts of blood flow through the ductus venosus during the first hours of life. Pressure measurements after catheterization via the umbilical vein have always shown a pressure gradient between portal sinus and the central veins localized at the level of the ductus venosus, indicating a significant narrowing of its lumen (Fig. 4). Indicator dilution studies (two-catheter technique) on infants during the early hours of life show, however, that an appreciable amount of the portal blood still flows across this vessel into the inferior vena cava (Jegier, Blankenship, and Lind, 1963). Thus, the 


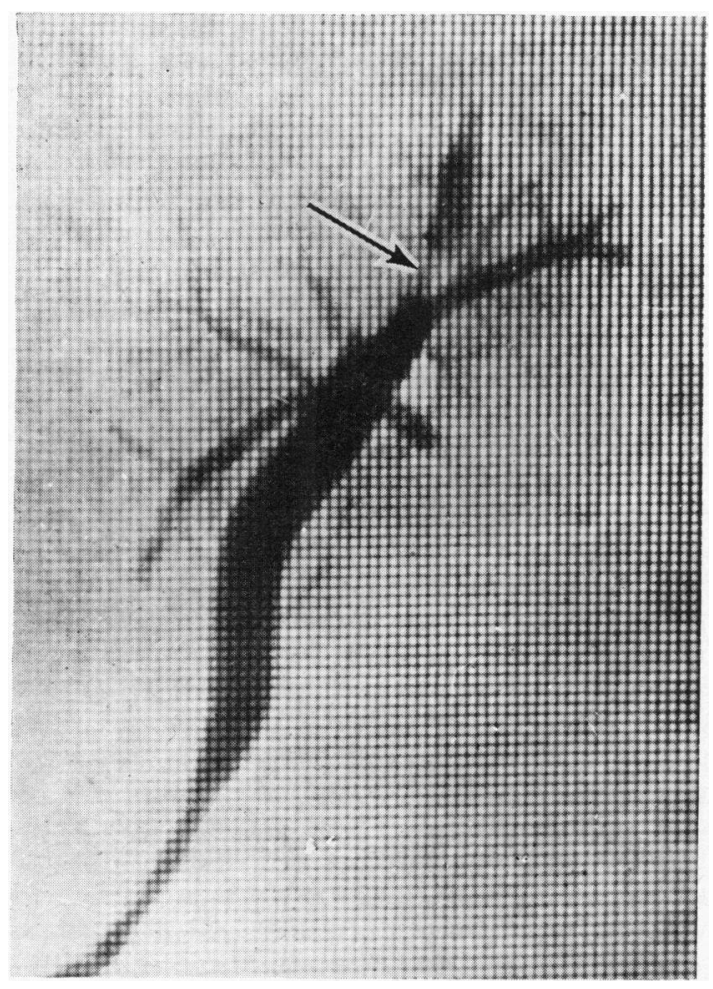

FIG. 3.-Angiogram from a newborn full-term infant. Contrast injection into the umbilical vein 5 minutes after birth. Left anterior oblique projection. The umbilical vein is well opacified, but in the distal portion of the ductus venosus where the 'sphincter' is located, the shadow is threadlike (arrow).

functional closure of the ductus venosus immediately after birth is not complete.

To understand a possible regulative function of the ductus venosus and the mechanism of its closure after birth a more detailed knowledge of the fine structure of the ductus venosus and especially of the amount and distribution of musculature in its wall is needed.

\section{Structure of Human Ductus Venosus and Morphological Observations on Functional and Organic Closure}

The ductus venosus in human foetuses and newborn infants is composed, as are most veins, mainly of collagenous networks (Meyer and Lind, 1965). In the wall of the duct these are very rich in elastic tissue, which forms many well-developed layers (Colour plate, Fig. A). However, the amount of the elastic elements differs from one part of the duct to another, and some sectors of its wall may contain only a few elastic layers. The elastic fibres are mainly arranged longitudinally (Colour plate, Fig. B), but at the origin of the ductus venosus in the portal sinus they change direction and assume, like the collagenous networks, a circular course. This course of the collagenous and elastic networks is especially evident in a cross-section of an already narrowed origin of the ductus venosus.

In contrast to the abundant elastic networks, the smooth musculature is scarcely developed in the duct wall. The smooth muscle cells form, as a rule, only small bundles, which are mainly circularly oriented. In only a few cases did we find, in some parts of the wall of the duct, well-developed smooth musculature which was practically the main component of a circumscribed section (Colour plate, Fig. C).

At the origin of the duct there was no more musculature than elsewhere, and there was no muscular sphincter. Our conclusions thus differ from those of Chacko and Reynolds (1953) and of

Colour Plate.-(A). Full-term newborn. The wall of the ductus venosus-as seen here in a longitudinal section of its distal third-consists mainly of two elements: a network of coarse collagenous bundles (red) and welldeveloped layers of longitudinal elastic fibres (black). Near the lumen (above) there is a thin layer of loose connective tissue. No smooth muscle cells are present. (Weigert's elastin + van Gieson stain. $\times 160$.) (B). 1-dayold full-term infant. Well-developed layers of longitudinal elastic fibres (dark brown) amidst collagenous networks (tan) in a tangenital section of the ductus wall. (Weigert's elastin + Haematoxylin-Phloxin-Tartrazin stain. $\times 170$.) (C). Two parts of the same cross-section of the ductus venosus (5-day-old premature infant, body length $38 \mathrm{~cm}$.). In one sector of the wall (on the left) a circumscribed marked development of the smooth muscle cells (greenish) embedded in the collagenous network (red) is seen. The remainder of the wall shows the usual structure (on the right) with well-developed elastic networks (black); no muscle bundles. (Verhoeff stain. $\times 170$.) (D). The border strip on the dorsal surface of the origin of the ductus venosus from the portal sinus. 8-hour-old infant. ( $\times 8 \cdot 5$.) (E). Full-term infant, several hours old. The cross-section of a border strip at the inlet of the ductus venosus into the portal sinus. The superficial layer of the slightly protruding border strip consists of loose connective tissue, which is poor in collagenous networks (red). No muscular elements are seen. (Weigert's elastin and van Gieson. $\times 160$.) (F). A 10-day-old premature infant, $45 \mathrm{~cm}$. The portal sinus contains well-developed smooth muscle bundles close to the origin of the ductus. These bundles (yellow) probably contribute to the postnatal narrowing of the sinus and the origin of the ductus as well. (Weigert's elastin and van Gieson stain. $\times 65$. 
A

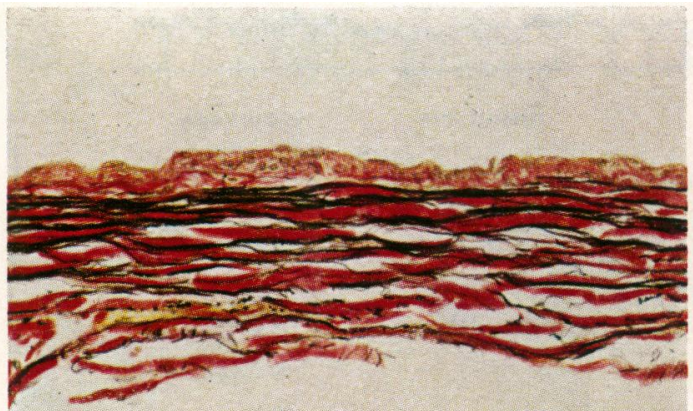

C

E

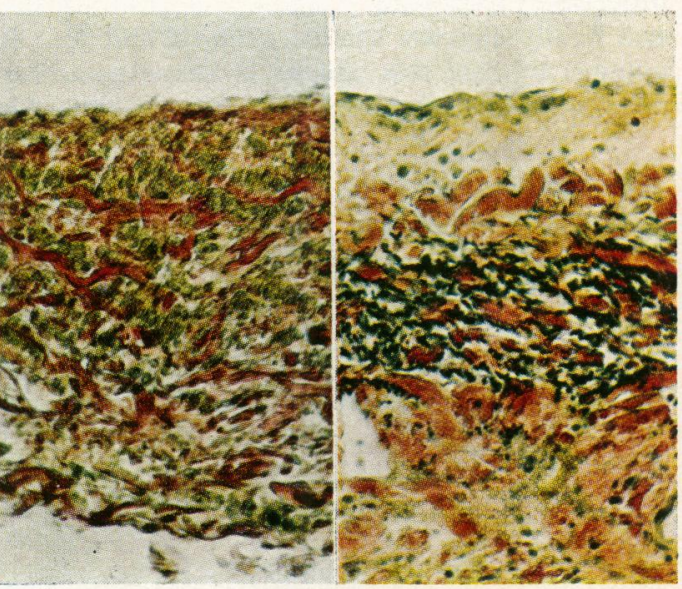

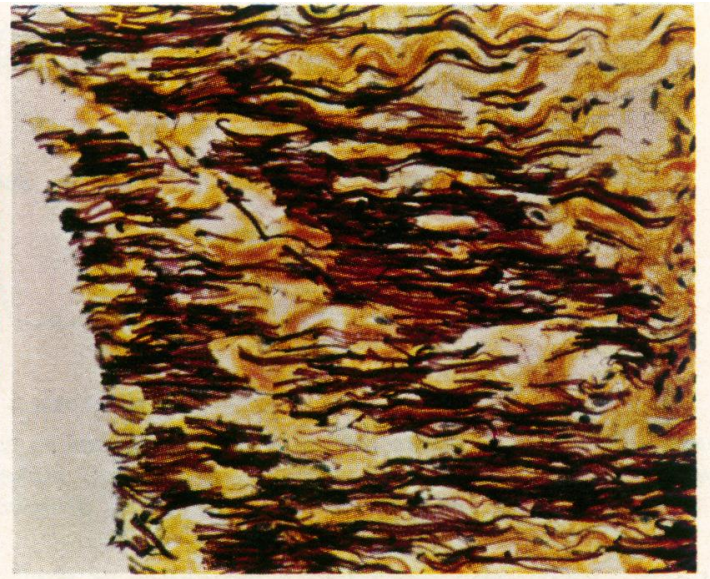

B
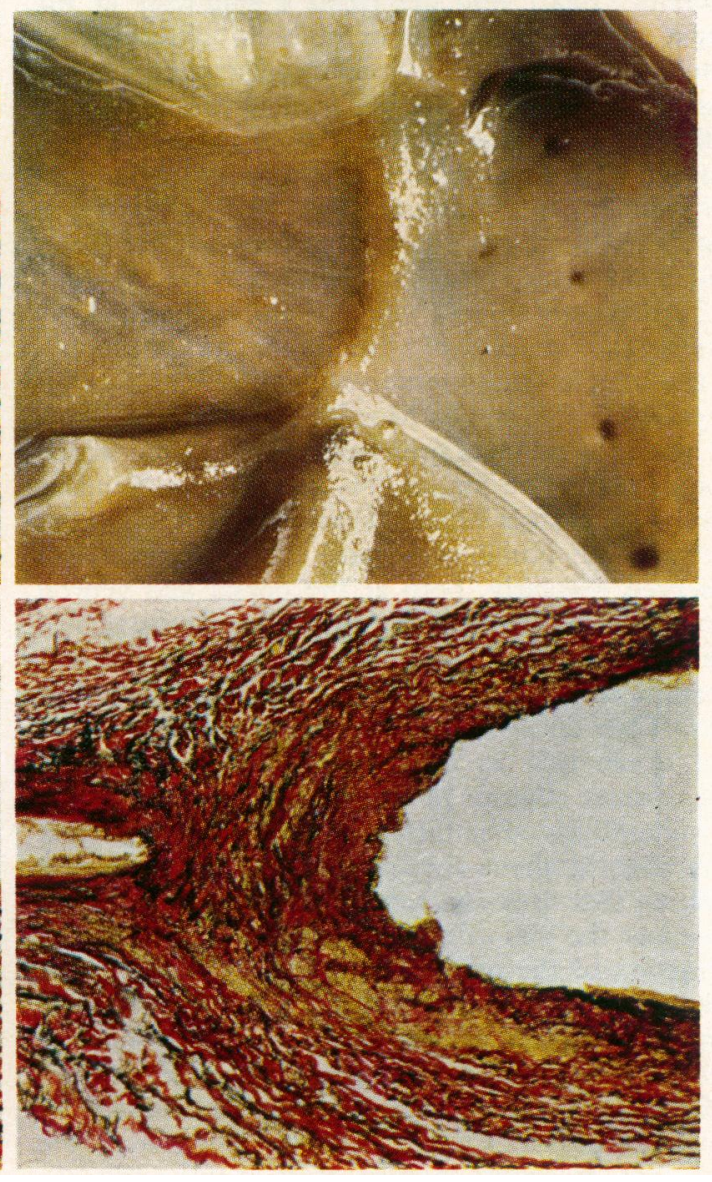

F

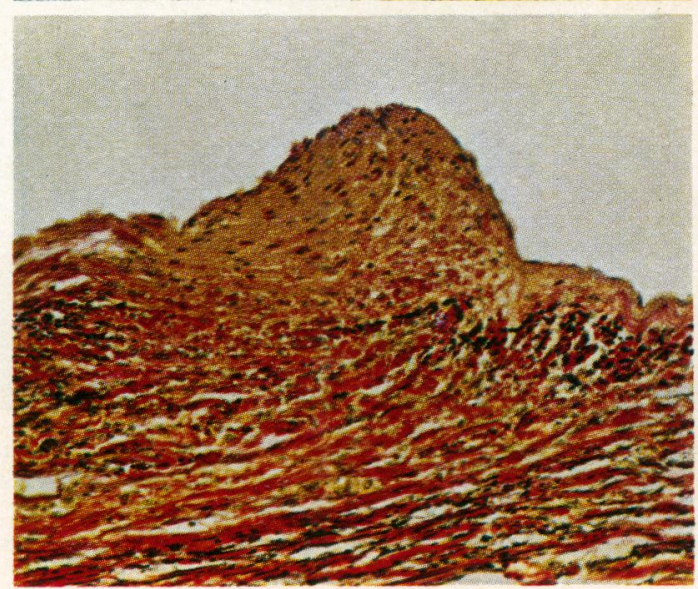

D

20

흠ㅁำ

잉

引

尺 


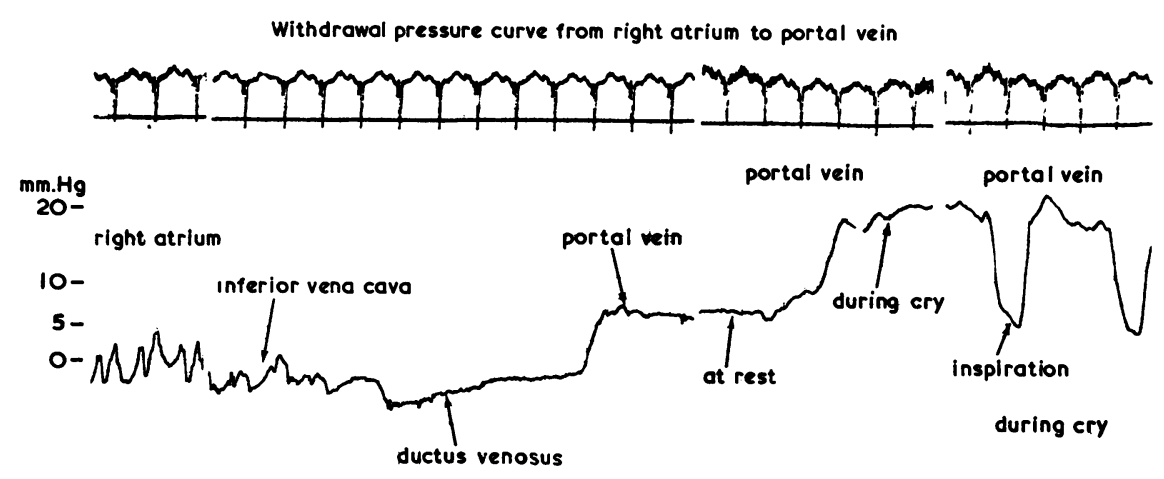

FIG. 4.-Withdrawal pressure curve from right atrium to portal vein in the newborn indicating that the ductus venosus is narrowed. The portal vein pressure is significantly higher than the blood pressure in the inferior vena cava. Note the great fluctuations in portal pressure during crying. Upper trace is ECG.

Adinolfi (1960) who described a sphincter at the origin of the human ductus venosus. Montagnani (1963) found an abundant development of the smooth musculature in the wall of the duct and defined it as an 'elastic-muscular structure', though observing no differentiated sphincter at the inlet of the duct. On the other hand, Barry (1963) was unable to detect any muscular elements either in the wall of the ductus or at its origin.

Furthermore, in our material we were unable to confirm the existence of a 'lip' or a 'rim', as observed at the inlet of the ductus venosus by Chacko and Reynolds (1953) and by Montagnani (1963). Thus, we could find no preformed structures which would close the origin of the ductus venosus immediately after birth. However, on the border between the portal sinus and ductus venosus we observed regularly, both at the dorsal and ventral sector of the inlet, slightly raised, narrow strips of the inner vascular wall, which, because of their location, we term 'border strips' (Colour plate, Fig. D). They consist of a loose, proliferating connective tissue rich in cells and include no smooth musculature (Colour plate, Fig. E).

Immediately after birth the border strips project only slightly above the level of the inner vascular wall, so that they can neither substantially narrow nor close the exit of the duct. However, after the retraction of the origin of the ductus venosus (see below) they protrude more and could aid in the functional closure. Later, they become important structural elements for the organic closure.

For the understanding of the mechanism of the functional closure of the ductus venosus, the successive postnatal changes of its opening into the portal sinus, as they can be observed macroscopically, are relevant. Originally, this opening of the ductus venosus is round or oval. Postnatally, with progressive narrowing it assumes an elliptical shape, and finally appears slit-like (Fig. 5 and 6). It is noteworthy that this change in shape coincides in time with the postnatal reduction of the blood

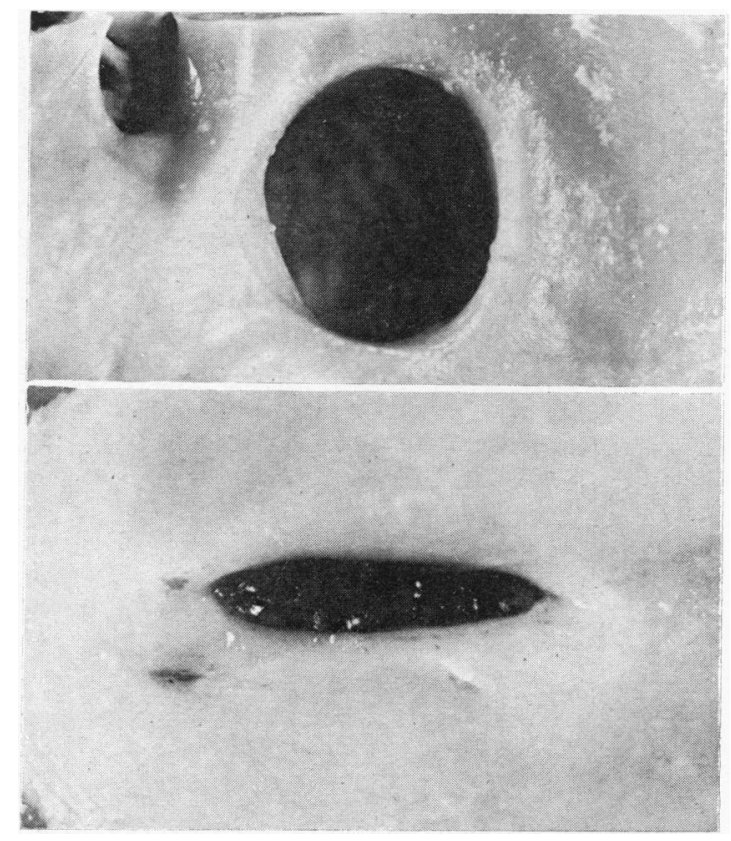

FIG. 5.-The postnatal change of the inlet of the ductus venosus in the portal sinus. The fully opened inlet (above), as seen after fixation under an intravascular pressure of about $50-60 \mathrm{~cm}$. of water, is round or oval (full-term stillborn $)$. ( $\times 11$.

Later (below), the inlet of the ductus venosus in the portal sinus appears slit-like (5-day-old full-term baby). Fixation after injection of $3 \%$ solution of gelatine under a pressure of $10 \mathrm{~cm}$. water. $(\times 11$. 
으

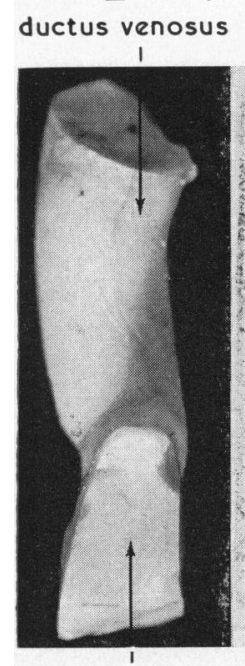

portal sinus $\underline{b}$

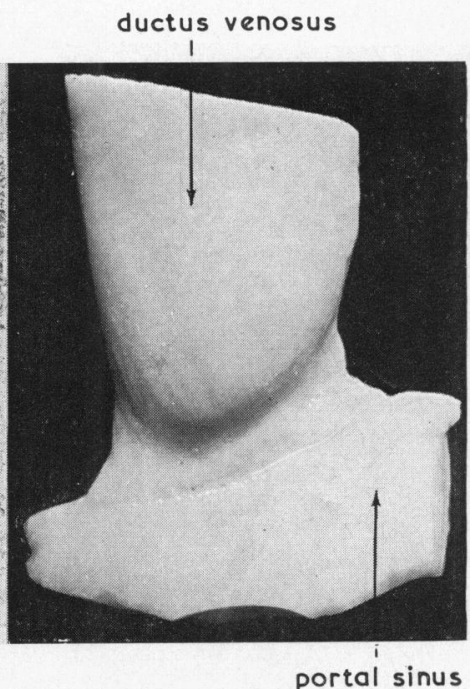

FIG. 6.- $a$. The lateral view of the barium-gelatine cast of the partly retracted origin of the ductus venosus and the adjacent portion of the portal sinus (full-term newborn at 45 minutes). b. Dorsal surface of the same cast. Corresponding to the elliptical shape of the partly closed orifice of the duct, its diameter appears shorter in the lateral view than in the dorsal or ventral view. $(\times 8$.

pressure in the portal sinus: before birth and perinatally the blood pressure in the umbilical vein, and consequently also in the portal sinus (i.e. umbilical recess), is about $20-30 \mathrm{~mm} . \mathrm{Hg}$. With the cessation of the umbilical circulation the blood pressure in the portal sinus falls to about $7-8 \mathrm{~mm} . \mathrm{Hg}$ and becomes equal to the pressure in the portal vein. It can be assumed that, following this marked fall in

pressure, retraction of the portal sinus, i.e. of the umbilical recess, occurs. Such retraction is all the more likely, since, after the umbilical circulation stops, both the blood pressure in the portal sinus and the flow through it are reduced. As a result of the reduction in calibre of the portal sinus, the opposite borders of the orifice of the ductus venosus come closer together, and the round or oval opening gradually assumes the slit-like shape mentioned above (Fig. 5, 7). The relation between the intravascular pressure and the width of the ductus venosus can be demonstrated post mortem, if contrast medium is injected through the umbilical vein. Cineradiographically, fall of blood pressure is seen to cause the lumen of the ductus venosus to collapse, and its inlet, the narrowest part of the duct, seems then completely closed (Fig. 8).

This passive process leading to functional closure of the duct seems to be reinforced by the action of smooth muscle in the portal sinus. Near the opening of the ductus venosus, as in other parts of the portal sinus, there are many small muscle bundles and, occasionally, larger bundles (Colour plate, Fig. F). These are reminiscent of the structures near the inlet of the ductus venosus in the lamb, which were noted by Barron (1942, 1944). Barron observed smooth muscle bundles arranged in a horse-shoe manner to form a sphincter-like structure. Although in human foetuses and newborn infants the larger muscle bundles near the origin of the duct can be found only occasionally and do not form a sphincter, the muscle bundles scattered in the wall of the portal sinus may as a whole contribute to the postnatal narrowing of the portal sinus and in this way to the functional closure of the ductus venosus.

The functional narrowing of the ductus venosus is followed by organic closure. According to our observations, the closure begins at the above-

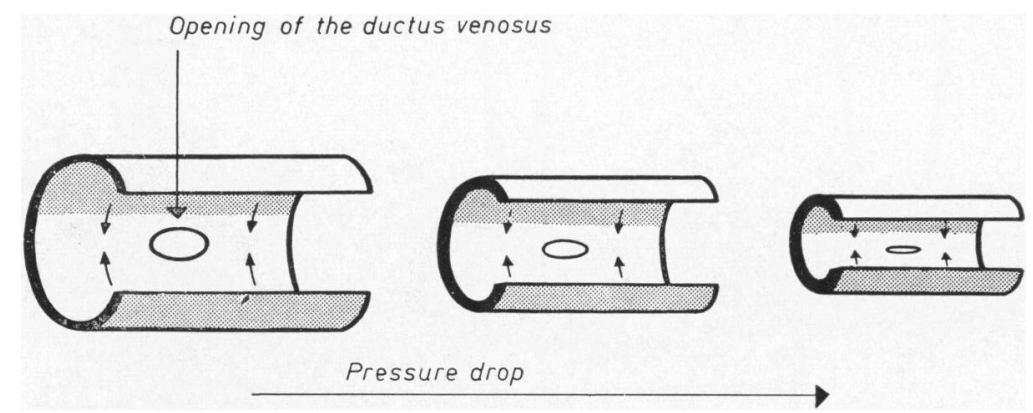

FIG. 7.-Schematic representation of the postnatal functional closure of the origin of the ductus venosus. Following the postnatal drop in pressure and blood flow in the portal sinus, its wall retracts and its lumen narrows. The opposite margins of the oval-shaped inlet of the ductus venosus come closer together and the inlet becomes slit-like. The arrows show the presumed direction of the elastic forces acting in the wall of the portal sinus. 


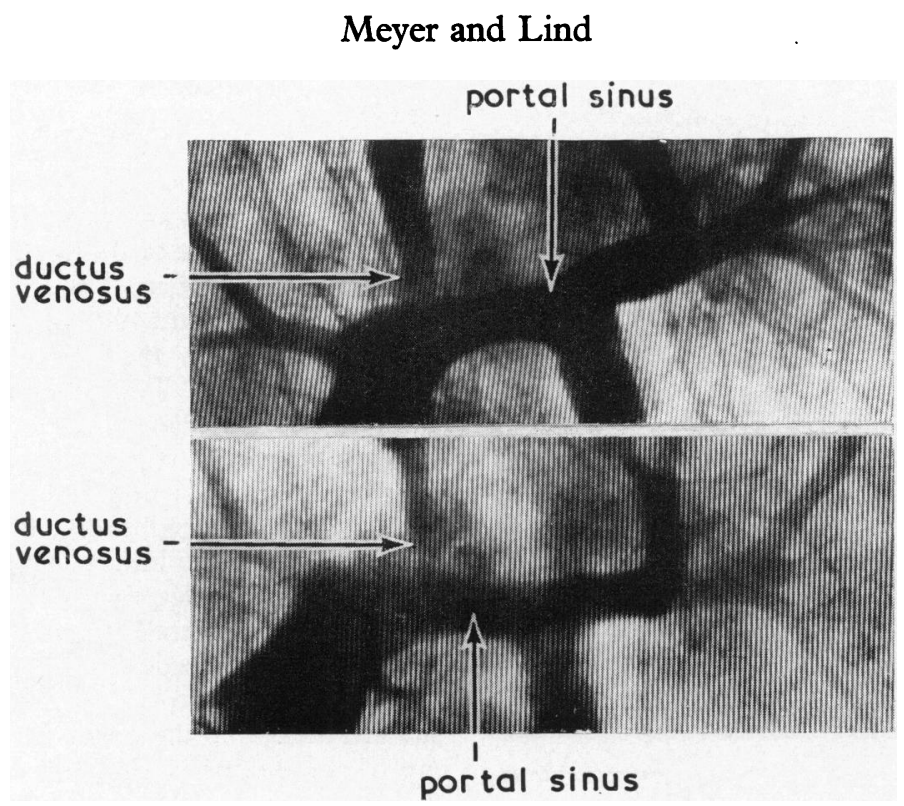

Fig. 8.-Post-mortem angiograms of the portal sinus and the ductus venosus. Above, ductus venosus at a greater injection pressure. Below, after a drop in pressure the origin of the ductus venosus is hardly seen.

mentioned border strips, the superficial layers of which, adjacent to the lumen, are composed mainly of fibroblast-like cells. The obliterative tissue proceeds from these elements. A few days after birth, the preformed parts of the border strips, which are richer in fibres and more compact, are already overlaid by a wide layer of a young loose connective tissue rich in cells and still poor in fibres.
The absence of a subendothelial elastic barrier, i.e. internal elastic membrane, in the duct presumably favours the development of the young connective tissue both in the area of the border strips and in the duct itself. Tissue proliferation, proceeding from both border strips, progressively narrows the residual opening of the duct (Fig. 9). The final adhesion of the proliferating border strips is

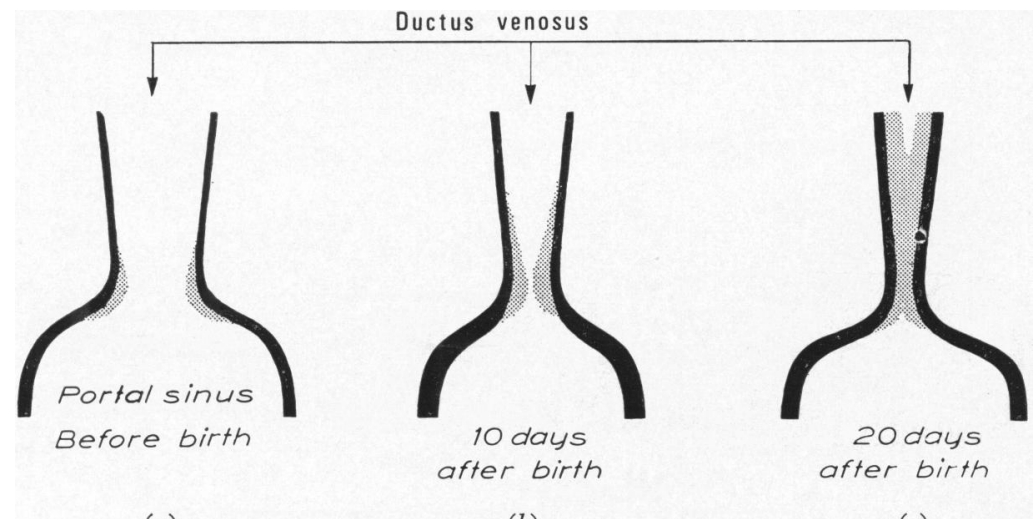

(a)

(b)

(c)

FIG. 9.-Schematic representation of the different stages of the organic closure of the ductus venosus. (a) At the wide, open origin of the duct the border strips (stippled) protrude only slightly into the lumen. (b) In the retracted and partly closed duct the proliferating tissue of the border strips significantly narrows the inlet of the duct. proliferating connective tissue fills the whole lumen of the ductus venosus.

(c) Later the young 
apparently aided by the necrobiotic changes that can often be observed on their surface. In the remaining proximal course of the ductus venosus the obliterating tissue proceeds from the loose subendothelial layer. We have observed no thrombosis in the narrowed or closed ductus venosus. According to our observations, final organic closure occurs between the 15 th and 20 th day of life.

\section{Summary}

During foetal life the ductus venosus provides a direct connexion between the umbilical vein and the inferior vena cava. A significant amount of the oxygenated umbilical venous blood from the placenta bypasses the liver through this channel.

The wall of the ductus venosus contains only small amounts of smooth muscle bundles. No muscular sphincter is found at its origin. Nor is there any evidence of other preformed structures, like the so-called lips sometimes mentioned in the literature, and which are said to obstruct the duct immediately after birth.

The postnatal functional closure of the ductus venosus appears to be a consequence of a decrease in pressure in the portal sinus, resulting in retraction and narrowing of its origin which thus assumes a slit-like appearance. This closure is, probably, reinforced by the muscular elements in the wall of the portal sinus near the origin of the duct.

The functional closure of the ductus venosus occurs during the first minutes after birth and is not complete. An appreciable amount of the portal venous blood is shunted through this channel during the first hours and perhaps days of life.

The organic closure of the ductus venosus begins at its narrow origin, with proliferation of the obliterating tissue in specially structured border strips. Closure is completed between the 15th and 20th days.

\section{REFERENCES}

Adinolfi, G. (1960). Contributo allo studio dello sfintere del dotto venoso nei feti a termine. Arch. Ostet. Ginec., 65, 457.

Amoroso, E. C., Dawes, G. S., Mott, J. C., and Rennick, B. R. (1955). Occlusion of the ductus venosus in the mature foetal lamb. F. Physiol. (Lond.), 129, 64P.

Barclay, A. E., Franklin, K. J., and Prichard, M. M. L. (1942). The mechanism of closure of the ductus venosus. Brit. F. Radiol., 15, 66.

Barcroft, J. (1946). Researches on Pre-Natal Life. Blackwell, Oxford.

Barron, D. H. (1942). The 'sphincter' of the ductus venosus. Anat. Rec., 82, 398.

- (1944). The changes in the fetal circulation at birth. Physiol. Rev., 24, 277.

Barry, A. (1963). The development of hepatic vascular structures. Ann. N.Y. Acad. Sci., 111, 105.

Blanc, W. B. (1960). Premature closure of the ductus venosus. Amer. F. Dis. Child., 100, 572.

Chacko, A. W., and Reynolds, S. R. M. (1953). Embryonic development in the human of the 'sphincter' of the ductus venosus. Anat. Rec., 115, 151.

Franklin, K. J., Barclay, A. E., and Prichard, M. M. L. (1940) Some observations on the cardio-vascular system in the viable foetal lamb. F. Anat. (Lond.), 75, 75.

Jegier, W., Blankenship, W., and Lind, J. (1963). Venous pressure in the first hour of life and its relationship to placental transfusion. Acta paediat. (Uppsala), 52, 485.

Lind, J. (1959). The human foetal circulation and its changes following birth. In Die physiologische Entwicklung des Kindes, ed. F. Linneweh. Springer, Berlin, Göttingen, Heidelberg.

- (1963). Changes in the liver circulation at birth. Ann. N.Y. Acad. Sci., 111, 110.

- -, Stern, L., and Wegelius, C. (1964). Human Foetal and Neonatal Circulation. Charles C. Thomas, Springfield, Illinois.

—, and Wegelius, C. (1949). Angiocardiographic studies on the human foetal circulation. A preliminary report. Pediatrics, 4, 391 .

- and - (1954). Human fetal circulation: changes in the cardiovascular system at birth and disturbances in the post-natal closure of the foramen ovale and ductus arteriosus. Cold Spr. Harb. Symp. quant. Biol., 19, 109.

MacMahon, H. E. (1960). The congenital absence of the ductus venosus: report of a case. Lab. Invest., 9, 128.

Meyer, W. W., and Lind, J. (1965). Über die Struktur und den Verschlussmechanismus des Ductus venosus. Z. Zellforsch., 67, 390.

Montagnani, C. A. (1963). Intrahepatic vascular pattern in the newborn infant. Ann. N.Y. Acad. Sci., 111, 121. 